\title{
Sustained Activity of Metabotropic Glutamate Receptor: Homer, Arrestin, and Beyond
}

\author{
Geehoon Chung ${ }^{1,2}$ and Sang Jeong Kim ${ }^{1,2,3,4}$ \\ ${ }^{1}$ Department of Physiology, Seoul National University College of Medicine, Seoul, Republic of Korea \\ ${ }^{2}$ Department of Brain and Cognitive Sciences, Seoul National University College of Natural Sciences, Seoul, Republic of Korea \\ ${ }^{3}$ Department of Biomedical Sciences, Seoul National University College of Medicine, Seoul, Republic of Korea \\ ${ }^{4}$ Neuroscience Research Institute, Seoul National University College of Medicine, Seoul, Republic of Korea
}

Correspondence should be addressed to Sang Jeong Kim; sangjkim@snu.ac.kr

Received 14 July 2017; Revised 10 October 2017; Accepted 31 October 2017; Published 21 November 2017

Academic Editor: Hee J. Chung

Copyright (c) 2017 Geehoon Chung and Sang Jeong Kim. This is an open access article distributed under the Creative Commons Attribution License, which permits unrestricted use, distribution, and reproduction in any medium, provided the original work is properly cited.

\begin{abstract}
When activated, metabotropic glutamate receptors (mGlus) exert long-lasting changes within the glutamatergic synapses. One mechanism is a tonic effect of downstream signal transduction pathways via sustained activation of mGlu itself. Like many other G protein-coupled receptors (GPCRs), mGlu can exist in a constitutively active state, which persists agonist independently. In this paper, we review the current knowledge of the mechanisms underlying the constitutive activity of group I mGlus. The issues concerning Homerla mechanism in the constitutive activity of group I mGlus and recent findings regarding the significant role of $\beta$-arrestin in sustained GPCR activity are also discussed. We propose that once in a state of sustained activation, the mGlu persistently activates downstream signaling pathways, including various adaptor proteins and kinases, such as $\beta$-arrestin and mitogen-activated protein kinases. In turn, these effector molecules bind to or phosphorylate the mGlu C-terminal binding domains and consequently regulate the activation state of the mGlu.
\end{abstract}

\section{Introduction}

Efficient transmission of information in the nervous system is mediated by various neurotransmitters and neuromodulators. Glutamate, the most abundant neurotransmitter in the nervous system, acts as an excitatory signal in the synapses and plays a key role in the regulation of neuronal activity. In the synaptic loci, glutamate released from presynaptic vesicles binds to postsynaptic glutamate receptors, and synaptic activation of the postsynaptic ionotropic glutamate receptors, such as $\mathrm{N}$-methyl-D-aspartate (NMDA) and $\alpha$-amino-3-hydroxy-5-methyl-4-isoxazolepropionic acid (AMPA) receptors, directly contributes to the generation of action potentials in the postsynaptic neurons. Activation of the metabotropic glutamate receptor ( $\mathrm{mGlu}$ ), on the other hand, exerts indirect long-lasting influences throughout the neuron, primarily via the activation of heterotrimeric $\mathrm{G}$ proteins $[1-3]$.
Based on intracellular signaling pathways, the eight subtypes of mGlus can be classified into three subgroups (I, II, and III). Among the eight mGlu subtypes, the most extensively studied $m$ Glus are $\mathrm{mGlu}_{1}$ and $\mathrm{mGlu}_{5}$, which constitute group I mGlus $[4,5]$. The activation of group I mGlus stimulates phospholipase C (PLC) $\beta$, resulting in activation of a diacylglycerol- (DAG-) mediated protein kinase C (PKC) pathway, and exerts calcium response by facilitating the opening of plasma membrane calcium channels and the release of inositol triphosphate- $\left(\mathrm{IP}_{3^{-}}\right)$mediated calcium from the intracellular calcium stores [6]. The intracellular signaling cascades activated by group I mGlus play an essential role in the plasticity of neuronal excitability [6]. This is achieved by endocannabinoid-mediated suppression of presynaptic vesicle release probability, modulation of the receptor and channel availability in the postsynaptic neuronal membrane, and alteration in the transcription of genes related to various regulatory signaling molecules [5]. 
Akin to many other GPCRs [7-10], mGlus exist in a state of equilibrium between being active or inactive, regardless of agonist binding [11-13]. As such, mGlus can show sustained activity under certain circumstances. The persistence of mGlu activity after agonist washout as well as the constitutive mGlu activity independent of agonist binding has been reported in previous studies [13-15]. The sustained cellular effects of mGlu activation are mediated by downstream effectors, including $\mathrm{G}$ proteins or $\beta$-arrestins, and play a critical role in modulating neuronal plasticity $[6,16-18]$. Further, previous studies have reported that the persistent effect of mGlu activation is involved in physiological function and pathological dysfunction of the nervous system $[11,14,19]$.

In this review, we will focus on the sustained activity of group I mGlu signaling and intracellular mechanisms underlying the persistent effect of receptor activation. We will review current knowledge regarding the significant role of the intracellular scaffold, Homerla, in constitutive activity of group I mGlus. Further, we will discuss recent findings of $\beta$-arrestin function in sustained $G$ protein activity in the intracellular GPCRs, addressing its possible relevance to the persistently active mGlu signaling. We conclude with a discussion of intracellular mGlu function and the suspected role of downstream mitogen-activated protein kinase (MAPK) signaling in the maintenance of sustained mGlu activity.

\section{Persistent Action of the mGlus following Activation}

The persistent activation is a common phenomenon among GPCRs $[9,20,21]$. Sustained $G$ protein signaling after agonist washout has been reported for many GPCRs. This longlasting action can be derived from the persistent effect of downstream cascades following agonist binding to the receptor, and/or agonist-independent persistent activation of the receptor itself. Previous studies have shown that the activation of mGlu downstream cascades exerts long-lasting influences on glutamatergic synaptic transmission, and persistent changes in synaptic efficacy elicited by mGlu activation are reversibly suppressed by mGlu antagonists [22]. For instance, a long-term depression (LTD) can be induced by the stimulation of group I mGlu using the agonist, 3,5-dihydroxyphenylglycine (DHPG), in hippocampal neurons. This group I mGlu-mediated LTD is fully or partially reversed by the application of the mGlu antagonists, such as $\alpha$ methyl-4-carboxyphenylglycine (MCPG), 2-amino-2-(3-cis and trans-carboxycyclobutyl-3-(9-thioxanthyl)propionic acid (LY393053), $\alpha$-amino-4-carboxy-2-methylbenzeneacetic acid (LY367385), or 2-methyl-6-(phenylethynyl)-pyridine hydrochloride (MPEP). The phenomenon is not specific to the group I mGlu. The group II and group III mGlu-mediated LTD is also reversed by representative antagonists [22]. These findings raise the possibility that prolonged alteration in neuronal activity induced by group I mGlu activation is mediated by the persistent activity of the mGlus themselves [14]. This suggested that the role of persistent activation can lead to modulation of neuronal activity in the physiological as well as pathological state $[12,14,23]$.
The necessary condition for this persistent activity might differ based on the neuronal state and mGlu subtypes. In the case of the $\mathrm{mGlu}_{5}$ in CA3 hippocampal neurons, DHPG application at a sufficiently high temperature $\left(30-31^{\circ} \mathrm{C}\right)$ for a sufficient period of time (>30 min) is necessary for the manifestation of persistent activation [15]. Under this condition, neuronal excitability was altered because of a change in state of the potassium channels and therefore persistent suppression of afterhyperpolarization (AHP), which is mediated by a p38 MAPK- and protein synthesis-dependent signaling pathway. The necessary condition (high temperature) in this case implicates that temperature-sensitive enzymes and/or ion channels might be involved in this $\mathrm{mGlu}_{5}$-mediated persistent AHP suppression [15, 24-26]. In the case of the $\mathrm{mGlu}_{1}$, the ion channel was transiently affected but the persistent change of state was not elicited by the same stimulation [15]. Interestingly, another study has reported that the persistent CA3 neuronal responses to the group I mGlu agonist DHPG were reversed by mGlu $_{1}$ antagonist LY367385 or (hydroxyimino)cyclopropa[b]chromen-1a-carboxylate ethyl ester (CPCCOEt) and to a lesser extent by the $\mathrm{mGlu}_{5}$ antagonist MPEP, indicating that the $\mathrm{mGlu}_{1}$ is primarily involved [14]. In spite of the inconsistency, these studies commonly implicate the persistent activity and functional relevance of group I mGlu to long-lasting changes in neuronal activity.

\section{Constitutive, Agonist-Independent Activity of mGlus}

Many GPCRs exhibit agonist-independent activity. Although the exact mechanisms underlying the sustained signaling of GPCRs have not been fully understood, many investigations on the phenomenon have revealed that constitutive activity is an intrinsic feature of GPCRs [7-10]. The sustained activation of GPCRs can be modulated by signaling molecules, as well as endogenous ligands, and plays a significant role in maintaining both physiological and pathological state.

Group I mGlus have been reported to show constitutive activity $[11,12,23,27]$. As a GPCR, the mGlu also has intracellular domains that can interact with numerous kinases, phosphatases, and proteins. These molecules modulate the action of the receptors, and many of them are shared by other GPCR signaling pathways. Constitutive activity of mGlus can result from changes in receptor conformation induced by these interacting molecules. Previous studies showed that mutation of specific allosteric binding domain residues results in conformational changes and modulates the constitutive activity of mGlus [28, 29]. Recently, it has been revealed that the constitutive activity of group I mGlus can be modulated by mGlus coupling to specific intracellular interacting molecules, such as the Homer family of scaffold proteins $[11,13]$.

\section{Involvement of Homer Proteins in the mGlus Constitutive Activity}

In the case of mGlu, the involvement of the Homer family of intracellular proteins is the most studied mechanism of the constitutive activity. Homer proteins are intracellular 
scaffolding proteins that interact with various membrane receptors including mGlus [30-32]. With the conserved Ena/VASP homology (EVH) 1 domain, Homer proteins bind to the C-terminal PPXXF motif of receptors and act as a scaffold for various intracellular effector interactions. The Homer family comprises of many alternative splicing variants from three Homer genes, and these multiple isoforms can be categorized into either long-form or short-form Homer proteins. The long-form Homer proteins (Homer $1 b, 1 c, 2$, and 3) have a coiled-coil domain and form dimers with other intracellular effectors. The short-form Homer protein (Homer 1a), in contrast, only has an EVH1 domain and lacks a coiled-coil domain. Homerla acts as a dominantnegative competitor for other long-form Homer proteins by binding to the receptors and disrupting intracellular signaling. The Homerla is expressed in an activity-dependent manner, whereas other long-form Homer proteins are constitutively expressed. Homerla is believed to counteract the hyperexcitability of neurons and thus play a key role in endogenous neuroprotection [32-36].

Other than such a homeostatic regulatory role, Homerla is also involved in the constitutive activation of the mGlu [11, 13]. As a dominant-negative competitor for other long-form Homer proteins binding to the mGlu, Homerla disrupts mGlu-Homer3 interaction when expressed. Because the Homer 3 is constitutively expressed and acts as a negative regulator of mGlu constitutive activity via stabilization of the receptor, disruption of mGlu-Homer3 binding by Homerla induction results in development of neuronal conditions for mGlu constitutive activation [11].

Although the involvement of Homer1a in the constitutive activity of mGlu has been reported, this concept does not clarify the basal mechanisms underlying constitutive activation of mGlu. The Homerla mechanism for the induction of constitutive activity depends on its dominantnegative effect on mGlu-Homer3 binding. The study of Homerla-mediated constitutive activity of mGlu was performed in the cerebellum, where basal Homer3 expression is known to be high [13]. As the expression of Homer3 differs depending on the brain regions and neuronal subtypes, it is speculated that the induction of constitutive mGlu activity by Homerla might be inconsistent depending on the cellular condition. If Homer3 binding stabilizes mGlu and blocks the constitutive activation of the receptor, and Homerla induces mGlu constitutive activity by disrupting mGlu-Homer3 binding, it is not appropriate to state that Homerla is a necessary condition for the constitutive activity of mGlu. Thus, in the neuronal condition where Homer3 is absent, the mGlu constitutive activity might be conserved even without the presence of Homerla. Rather, regarding the original Homerla action of disrupting the binding of the mGlu to various interacting molecules, Homerla would prevent the activation of certain intracellular pathways downstream in the mGlu signaling pathway. For instance, the disruption of mGlu interaction with Homer1b/c or Homer2 would affect calcium signaling and MAPK phosphorylations [37-39]. The degree of interruption in the mGlu downstream pathways by Homer proteins varies among different neurons and on the composition of the signaling pathways [39]. In that, the expression of Homerla can decrease [40-42] as well as increase [13, 41, 43] the rise in calcium levels in response to mGlu stimulation, depending on the neuronal subtype [39]. Furthermore, the stimulation of mGlus activates several downstream pathways $[16,44]$, and Homer binding to mGlu does not uniformly activate or deactivate all these pathways [44]. Therefore, the functional effect of Homer on the sustained downstream activation of the mGlu might be pathway specific.

\section{The Role of the $\beta$-Arrestin Pathway}

We speculate that $\beta$-arrestin might be involved in the modulation of mGlu activity. In the classical view, $\beta$-arrestin had been regarded as a terminator of GPCR activity. According to this classical concept, agonist activation of the surface GPCR leads to GPCR kinase- (GRK-) induced phosphorylation of the receptor, followed by $\beta$-arrestin binding, and the binding of $\beta$-arrestin to the receptor results in desensitization and internalization of the receptor [21]. However, it is now clear that the action of $\beta$-arrestin is not limited to the desensitization or internalization of the receptor [45]. $\beta$-Arrestin acts as an adaptor or a scaffold, and its binding to the GPCR can activate signaling pathways independent of the G protein, to induce cellular change $[46,47]$. $\beta$-Arrestin interacts with most of the GPCRs including mGlus $[16,17]$. A recent study showed that the $\beta$-arrestin-induced $G$ proteinindependent signaling pathways of group I mGlu play a significant role in LTD in hippocampal neurons, and the involved pathways differ between CA1 neurons and CA3 neurons [17]. The authors of the study found that genetic ablation of $\beta$-arrestin2 results in deficits in LTD mediated by $\mathrm{mGlu}_{1}$ in CA3 neurons and by $\mathrm{mGlu}_{5}$ in CA1 neurons. They also have reported that the $\beta$-arrestin 2 knockout mice have a deficiency in long-term potentiation (LTP) induced by low-frequency stimulation, paired stimulation of mossy fiber inputs to CA3 pyramidal neurons [48], but not in LTP induced by high-frequency stimulation [17]. An early study of CA3 pyramidal neurons revealed that NMDA receptor potentiation by $\mathrm{mGlu}_{5}$ is mediated by a $\mathrm{G}$ proteindependent pathway, whereas potentiation by $\mathrm{mGlu}_{1}$ is mediated by a $G$ protein-independent pathway [49]. The study demonstrated that the DHPG application could induce LTP under conditions of $\mathrm{G}$ protein blockade using GDP $\beta$ S. This DHPG-LTP was blocked by the Src inhibitor. The authors discussed that the $\beta$-arrestin-mediated recruitment of Src kinase underlies the $\mathrm{G}$ protein-independent action of $\mathrm{mGlu}_{1}$ $[49,50]$. Therefore, we can speculate that the $\beta$-arrestin downstream pathways of mGlu might be in an active state even under circumstances in which mGlu ceased its G protein-dependent pathways.

In addition to the activation of $\mathrm{G}$ protein-independent signaling pathways, the coupling of $\beta$-arrestin to mGlus might determine the activity status of the receptors. According to previous studies, GPCRs with weak coupling to $\beta$ arrestin (class A GPCRs) interact transiently with $\beta$-arrestin due to relatively low affinity and thus are recycled back to the plasma membrane shortly after endocytosis. GPCRs with stronger binding affinity to $\beta$-arrestin (class B GPCRs), on 


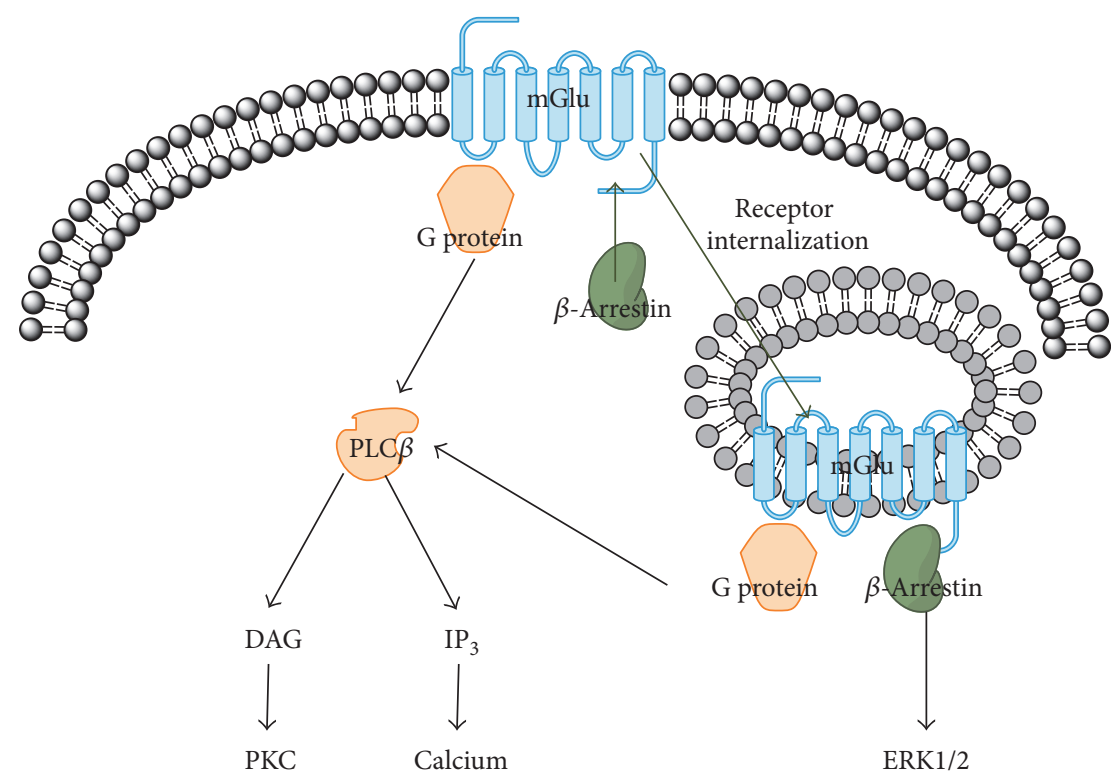

Figure 1: Proposed model of sustained mGlu activation. $\beta$-Arrestin binding to the mGlu internalizes the receptor. With stable binding to the mGlu C-terminal, $\beta$-arrestin mediates receptor internalization and activates ERK1/2 MAPK, but does not induce desensitization of G protein signaling. In this condition, the $\beta$-arrestin tightly binds only to the $\mathrm{C}$-terminal tail but not to the transmembrane region, and thus the $\mathrm{G}$ protein can simultaneously bind to the transmembrane core of the receptor. The downstream pathways are activated without interfering with each other. The convergence of the downstream pathways on common effectors and their reciprocal interactions are omitted in this figure.

the other hand, show stable coupling and thus have been thought to experience endosomal degradation following $\beta$ arrestin-induced endocytosis $[9,20,51]$. Recent studies, however, have challenged this classical concept of $\beta$-arrestinmediated cessation of GPCR activity. According to the studies, the binding of $\beta$-arrestin to GPCRs results in sustained activity of the G protein, mainly in the internalized GPCRs $[8,9]$. In this new concept, $\beta$-arrestin and the $G$ protein can bind simultaneously to the GPCR. This is achieved by $\beta$-arrestin binding to the $\mathrm{C}$ terminus and the $\mathrm{G}$ protein binding to the transmembrane core of the receptor [9]. The binding of $\beta$-arrestin to the $\mathrm{C}$-terminal tail mediates receptor internalization and intracellular signaling, but does not induce desensitization of $\mathrm{G}$ protein signaling $[8,9,20]$. Thus, the high affinity of the C-terminal tail of the class B GPCRs to $\beta$-arrestin allows for the condition in which the G protein couples with the transmembrane core and simultaneously, $\beta$-arrestin couples with the C-terminal, which results in internalization of the receptor by $\beta$-arrestin and conserved $\mathrm{G}$ protein signaling in the internalized receptor $[9,20]$. Consequently, the simultaneous activation of $G$ proteindependent and $G$ protein-independent signaling pathways can occur in the internalized GPCR [9]. Although the interaction status of the transmembrane core and C-terminal tail to the $G$ protein and $\beta$-arrestin in active mGlu is unclear, $\beta$-arrestin-mediated sustained signaling in the internalized GPCRs suggests a feasible mechanism for the constitutive activity (Figure 1).

$\beta$-Arrestin is also critically involved in modulating the plasticity of glutamatergic synaptic transmission $[16,17]$. A recent study showed that the $\beta$-arrestin pathway is required for a certain type of group I mGlu-mediated plasticity, which involves the extracellular signal-regulated kinase (ERK) pathway and is mediated by $\mathrm{mGlu}_{1}$ in the CA1 neurons and $\mathrm{mGlu}_{5}$ in the CA3 neurons [17]. We speculate that $\beta$-arrestin is further involved in the constitutive activity of the mGlus.

\section{Involvement of Intracellular $\mathrm{mGlu}_{5}$}

Recently revealed intracellular activity of $\mathrm{mGlu}_{5}$ supports the idea above. According to the studies, more than $60 \%$ of $\mathrm{mGlu}_{5}$ are located in the intracellular site $[52,53]$, and activation of the intracellular mGlu $_{5}$ leads to sustained cytosolic calcium responses [53-56]. Regarding the $\beta$-arrestinmediated sustained activity of GPCR that takes place with receptor internalization, the high composition ratio of intracellular $\mathrm{mGlu}_{5}$ inspires the idea that the intracellular $\mathrm{mGlu}_{5}$ activity is correlated with $\beta$-arrestin binding and sustained receptor signaling.

This intracellular $\mathrm{mGlu}_{5}$ activity plays a significant role in maintaining physiological and pathological plasticity during hippocampal LTD [54] and nerve injury-induced hyperexcitability of spinal neurons [53]. Interestingly, the signaling cascades induced by intracellular $\mathrm{mGlu}_{5}$ activation are distinct from the downstream signaling of $\mathrm{mGlu}_{5}$ in the plasma surface membrane $[55,56]$. Only intracellular $\mathrm{mGlu}_{5}$, not surface membrane $\mathrm{mGlu}_{5}$, causes ERK1/2 phosphorylation. This was demonstrated by the upregulation of ERK1/2 phosphorylation in response to the treatment of membrane-permeable agonist, quisqualate, in the presence of impermeable, nontransported antagonist, LY393053. The quisqualate-mediated upregulation of ERK1/2 phosphorylation could be blocked by the membrane-permeable antagonist MPEP. Conversely, the impermeable, nontransported agonist, DHPG, could 
not induce an increase in ERK1/2 phosphorylation. Similar discrepancies regarding ERK1/2 activation have been shown in a recent study of the $\beta$-arrestin-dependent downstream signaling pathway of $\mathrm{mGlu}_{5}$ activation [16].

\section{ERK1/2 MAPK Pathway}

In the signaling cascades of many GPCRs, G protein and $\beta$-arrestin-mediated pathways share common downstream effectors of ERK1/2 MAPK [57-59]. The binding of $\beta$ arrestin to activated GPCRs contributes to ERK1/2 phosphorylation, and sustained phosphorylation of ERK1/2 promotes GPCR internalization and constitutive signaling $[57,59-63]$. In the case of the $\mathrm{mGlu}_{1 / 5}$, agonist stimulation of the receptor results in ERK1/2 phosphorylation, which plays a significant role in the synapse [64-66]. This ERK1/2 activation is unaffected or only partially affected by inhibitors of PLC [38], which is a downstream effector of the G proteinmediated pathway [46]. Recent studies showed that $\mathrm{mGlu}_{5^{-}}$ mediated ERK1/2 activation was completely blocked by genetic reduction of $\beta$-arrestin2 [16, 17]. This suggests that the $\mathrm{mGlu}_{5}$-mediated ERK1/2 activation is $\beta$-arrestin pathway-dependent but not $G$ protein pathway-dependent [16]. As discussed above, this biased involvement for the phosphorylation of ERK1/2 is a shared characteristic in studies of intracellular $\mathrm{mGlu}_{5}$ activation and $\mathrm{mGlu}_{5}$-mediated $\beta$ arrestin signaling pathway.

Interestingly, activated ERK, in turn, regulates the binding of $\beta$-arrestin and Homer proteins to the receptor. The actions of $\beta$-arrestin on the GPCRs are regulated by an ERK-mediated feedback mechanism, as activated ERK preferentially phosphorylates receptor-bound $\beta$-arrestin $[46,67$, 68] and regulates its function [62]. Furthermore, activated ERK1/2 phosphorylates the serine-proline motif of $\mathrm{mGlu}_{1}$ and $\mathrm{mGlu}_{5}$, and the phosphorylation sites include the Homer binding site of mGlus C-terminal $[44,69]$. Thus, it is likely that once the $\beta$-arrestin pathway of intracellular mGlu is sufficiently activated, subsequent ERK activation would affect receptor coupling to $\beta$-arrestin and Homer proteins and eventually modulate the downstream signaling of mGlus (Figure 2). Whether the ERK-induced phosphorylation of Homer binding site of mGlu results in activation or deactivation of mGlu signaling might be case specific, as Homer modulation of mGlu signaling would differ based on neuronal conditions $[39,69]$. We propose that, under certain circumstances, binding of Homer and $\beta$-arrestin to the receptor adjusted by kinase phosphorylation would lead to sustained activation of the mGlu.

\section{Regulation of the Interactions}

The coupling of the Homer proteins to the receptor is affected by phosphorylation of the binding sites. In group I mGlu, the proline-directed kinases, such as ERK1/2 and cyclin-dependent kinase (CDK) 5, phosphorylate group I mGlu at the Homer binding site and control the downstream signaling pathways $[44,70]$. A multidomain scaffolding protein called Presol binds these proline-directed kinases and regulates Homer-mGlu binding [44]. Furthermore,

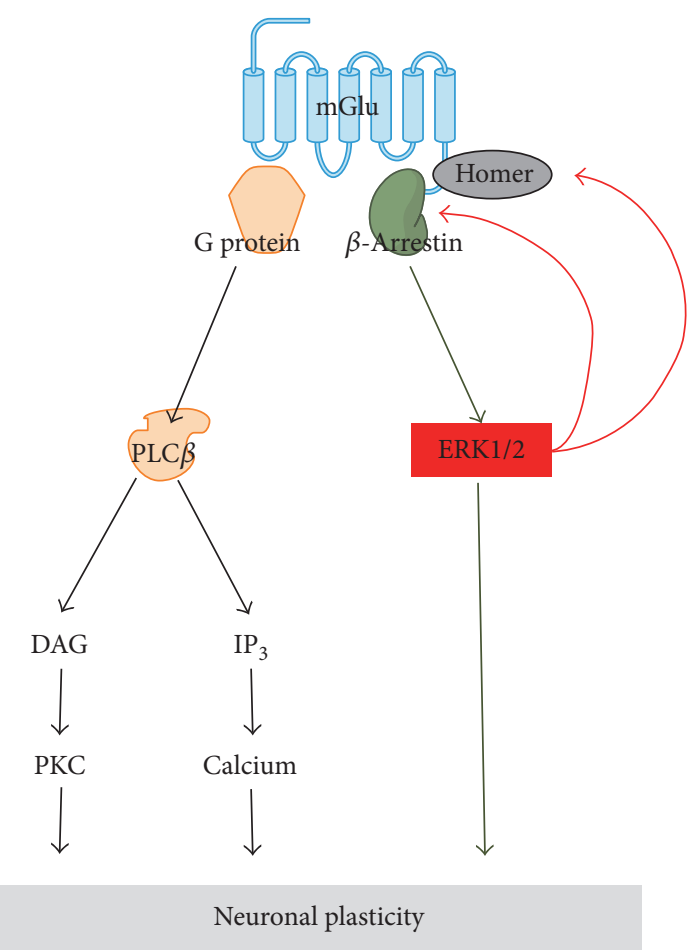

FIGURE 2: Feedback modulation of mGlu activity by ERK1/2. Stable binding of $\beta$-arrestin to the receptor upregulates ERK1/2 activation, whereas transient binding of $\beta$-arrestin downregulates it. The activated ERK1/2 preferentially phosphorylates receptor-bound $\beta$-arrestin and regulates its function. In addition, the activated ERK1/2 phosphorylates the Homer binding site of mGlus C-terminal. These feedback mechanisms might play a role in keeping the mGlu persistently active.

expression of Homerla after the induction of LTP in neurons present in the hippocampal dentate gyrus requires the ERK1/ 2 cascade [71]. As such, the interaction between kinases and proteins plays an important role in regulating the expression of Homer proteins and their interaction with mGlus. Since the Preso1-mediated regulation of Homer binding does not influence the surface expression of mGlus [44], it is unlikely that the downstream activation of the Homer-mediated mGlu directly recruits $\beta$-arrestin. Rather, it is speculated that the Homer-mediated and the $\beta$-arrestin-mediated pathways affect each other by the phosphorylation of the receptor and each protein. Importantly, the proline-directed kinases, which mediate mGlu phosphorylation at the Homer binding site, can be activated by numerous signaling pathways and are not specific to the receptor. This suggests the possibility of receptor crosstalk [44] and interaction with $\beta$-arrestin signaling. The binding of $\beta$-arrestin to the mGlus critically affects ERK1/2 activation via Raf signaling and protein synthesis following receptor activation. In return, $\beta$-arrestin signaling is affected by the ERK-mediated feedback control [62]. Interestingly, $\beta$-arrestin has two different modes of action in the regulation of ERK. A recent study of $M_{1}$ muscarinic acetylcholine receptors revealed the bidirectional control of ERK by $\beta$-arrestin binding to the receptor, showing that the stable binding of the $\beta$-arrestin upregulates ERK1/2 expression, whereas transient binding downregulates it [72]. Although 
details regarding $\beta$-arrestin binding to the mGlus during receptor activation are still unclear, this raises the prospect that the sustained activity of the mGlu is regulated by the functional interaction between Homer proteins and $\beta$-arrestin, which is balanced by ERK activation.

\section{Effects of the Interactions}

Proteins responsible for long-term expression of synaptic plasticity are rapidly translated in response to mGlu activation. Disrupted regulation, as well as excessive protein synthesis, can result in neuronal disorders [73]. Regarding the role that activated ERK1/2 plays in the regulation of gene expression, the signaling cascades involved in ERK activation would directly affect mGlu-mediated protein synthesis.

Although the binding of Homerla to the group I mGlu leads to constitutive activation in certain circumstances [13], the consequence is manifested by the G proteindependent downstream cascades, and not the ERK activation cascade. We speculate that the constitutive downstream activation of the $\mathrm{G}$ protein cascades is just one of the many possible consequences of Homerla binding to mGlu. This view is supported by the effects of Homer proteins and $\beta$-arrestin on the Ras-mediated activation of the ERK1/2. The Ras protein transduces signals from activated GPCRs to the cytoplasm and nucleus and contributes to the induction of various effector molecules, including MAPKs [74]. In many GPCRs, the Ras-dependent activation of the ERK1/2 MAPK pathway requires Src kinase signaling [59], and the interaction between $\beta$-arrestin and Src kinase plays an important role in this GPCR-Src-ERK1/2 pathway $[49,70]$. In addition, $\beta$-arrestin directly binds to c-Raf [68] and relieves the autoinhibition of the kinase even without Ras, which leads to the activation of the ERK cascade [75]. In the case of the mGlu, it has been proposed that $\beta$-arrestin acts as a scaffold to couple the Src kinase to the activated mGlu $[17,49,71]$ and thus is required for mGlu-mediated ERK1/2 activation [16]. Interestingly, upon activation of the $\mathrm{mGlu}_{5}$ in striatal neurons, only a small portion of ERK $1 / 2$ is activated by the PLC $\beta$ / $\mathrm{IP}_{3}$ /calcium-dependent pathway [38], which is a $\mathrm{G}$ proteinmediated cascade [16]. In the same condition, much stronger ERK1/2 activation is achieved by the calcium-independent pathway, in a Homer1b/c-dependent manner [38]. Since the ERK1/2 activation is $\beta$-arrestin pathway-dependent, this implicates the crosstalk between the Homer1b/c and $\beta$ arrestin downstream pathways. In this neuronal condition, Homerla binding to mGlu would negatively regulate ERK1/ 2 activation via inhibition of Homer $1 \mathrm{~b} / \mathrm{c}$ binding to mGlu. Indeed, Homerla strongly attenuates mGlu-dependent activation of ERK1/2 in the spinal cord [40]. Notably, the disruption of mGlu-Homer interactions selectively blocks the phosphoinositide 3-kinase- (PI3K-) Akt-mammalian target of rapamycin (mTOR) pathway but not the ERK pathway in hippocampal neurons, suggesting the region-specific role of Homer in mGlu signaling [76]. As a read-out of the protein synthesis downstream of $\mathrm{mGlu}_{5}$ activation, the ERK change implicates distinct mode of actions of the $\mathrm{mGlu}_{5}$ following its interaction with Homer proteins.
The functional consequences of the interaction are manifested by various physiological and pathological responses in neurons. The glutamate-induced protective signaling of $\mathrm{mGlu}_{1}$ is mediated by sustained, $\beta$-arrestin-mediated ERK activation [77]. In the case of Homer, the binding of the Homer protein to the phosphoinositide 3 kinase enhancer (PIKE) following quisqualate- or DHPG-induced activation of group I mGlu activates PI3K and prevents neuronal apoptosis [78]. Therefore, disruption of this interaction would affect the basal viability of the neuron. In addition, the mechanisms of the group I mGlu-mediated synaptic plasticity involve $\beta$-arrestin [16, 17] and the Homer protein [76]. These interactions are associated with neuronal diseases such as fragile $\mathrm{X}[16,27,76]$, chronic pain $[40,79,80]$, and addiction [81, 82]. Although these findings suggest the involvement of sustained activation, direct implication of sustained mGlus activity in the regulation of the synaptic transmission has not yet been established.

\section{Conclusion}

Constitutive activity of mGlu plays a critical role in neuronal responses. The coupling of mGlus to effector molecules including $\mathrm{G}$ proteins or $\beta$-arrestins not only mediates downstream effectors but also determines the activity of the mGlus itself. These effectors coupling to the mGlus and activation following downstream pathways could be modulated by reciprocal interactions between the binding molecules including kinases, phosphatases, and proteins. We propose that the Homer proteins, ERK1/2 MAPK, and $\beta$-arrestin affect each other and regulate the constitutive activity of mGlu. This regulation would occur in the internalized mGlu following sufficient receptor activation, and the C-terminal binding to interacting molecules would modulate the implementation of downstream signaling.

\section{Conflicts of Interest}

The authors declare that there is no conflict of interest regarding the publication of this paper.

\section{References}

[1] C. M. Gladding, S. M. Fitzjohn, and E. Molnar, "Metabotropic glutamate receptor-mediated long-term depression: molecular mechanisms," Pharmacological Reviews, vol. 61, no. 4, pp. 395-412, 2009.

[2] C. Lüscher and K. M. Huber, "Group 1 mGluR-dependent synaptic long-term depression: mechanisms and implications for circuitry and disease," Neuron, vol. 65, no. 4, pp. 445459, 2010.

[3] S. S. Willard and S. Koochekpour, "Glutamate, glutamate receptors, and downstream signaling pathways," International Journal of Biological Sciences, vol. 9, no. 9, pp. 948-959, 2013.

[4] T. M. Piers, D. H. Kim, B. C. Kim, P. Regan, D. J. Whitcomb, and K. Cho, "Translational concepts of mGluR5 in synaptic diseases of the brain," Frontiers in Pharmacology, vol. 3, p. 199, 2012.

[5] H. Wang and M. Zhuo, "Group I metabotropic glutamate receptor-mediated gene transcription and implications for 
synaptic plasticity and diseases," Frontiers in Pharmacology, vol. 3, p. 189, 2012.

[6] C. M. Niswender and P. J. Conn, "Metabotropic glutamate receptors: physiology, pharmacology, and disease," Annual Review of Pharmacology and Toxicology, vol. 50, no. 1, pp. 295-322, 2010.

[7] G. Corder, S. Doolen, R. R. Donahue et al., "Constitutive $\mu$ opioid receptor activity leads to long-term endogenous analgesia and dependence," Science, vol. 341, no. 6152, pp. 1394-1399, 2013.

[8] C. T. Gilliland, C. L. Salanga, T. Kawamura, J. Trejo, and T. M. Handel, "The chemokine receptor CCR1 is constitutively active, which leads to $G$ protein-independent, $\beta$-arrestinmediated internalization," Journal of Biological Chemistry, vol. 288, no. 45, pp. 32194-32210, 2013.

[9] T. ARB, B. Plouffe, T. J. Cahill 3rd et al., "GPCR-G protein$\beta$-arrestin super-complex mediates sustained $G$ protein signaling," Cell, vol. 166, no. 4, pp. 907-919, 2016.

[10] F. J. Meye, G. M. J. Ramakers, and R. A. H. Adan, "The vital role of constitutive GPCR activity in the mesolimbic dopamine system," Translational Psychiatry, vol. 4, no. 2, p. e361, 2014.

[11] L. Fagni, F. Ango, L. Prezeau, P. F. Worley, J.-P. Pin, and J. Bockaert, "Control of constitutive activity of metabotropic glutamate receptors by Homer proteins," International Congress Series, vol. 1249, pp. 245-251, 2003.

[12] I. Panaccione, R. King, G. Molinaro et al., "Constitutively active group I mGlu receptors and PKMzeta regulate synaptic transmission in developing perirhinal cortex," Neuropharmacology, vol. 66, pp. 143-150, 2013.

[13] F. Ango, L. Prézeau, T. Muller et al., “Agonist-independent activation of metabotropic glutamate receptors by the intracellular protein Homer," Nature, vol. 411, pp. 962-965, 2001.

[14] S. R. Young, S.-C. Chuang, W. Zhao, R. K. S. Wong, and R. Bianchi, "Persistent receptor activity underlies group I mGluR-mediated cellular plasticity in CA3 neuron," Journal of Neuroscience, vol. 33, no. 6, pp. 2526-2540, 2013.

[15] S. R. Young, R. Bianchi, and R. K. S. Wong, "Signaling mechanisms underlying group I mGluR-induced persistent AHP suppression in CA3 hippocampal neurons," Journal of Neurophysiology, vol. 99, no. 3, pp. 1105-1118, 2008.

[16] L. J. Stoppel, B. D. Auerbach, R. K. Senter, A. R. Preza, R. J. Lefkowitz, and M. F. Bear, " $\beta$-Arrestin2 couples metabotropic glutamate receptor 5 to neuronal protein synthesis and is a potential target to treat fragile X," Cell Reports, vol. 18, no. 12, pp. 2807-2814, 2017.

[17] A. G. Eng, D. A. Kelver, T. P. Hedrick, and G. T. Swanson, "Transduction of group I mGluR-mediated synaptic plasticity by $\beta$-arrestin 2 signalling," Nature Communications, vol. 7 , p. 13571, 2016.

[18] K. A. Newell and N. Matosin, "Rethinking metabotropic glutamate receptor 5 pathological findings in psychiatric disorders: implications for the future of novel therapeutics," BMC Psychiatry, vol. 14, no. 1, p. 23, 2014.

[19] R. Bianchi, S.-C. Chuang, W. Zhao, S. R. Young, and R. K. S. Wong, "Cellular plasticity for group I mGluR-mediated epileptogenesis," The Journal of Neuroscience, vol. 29, no. 11, pp. 3497-3507, 2009.

[20] T. J. Cahill 3rd, A. R. Thomsen, J. T. Tarrasch et al., "Distinct conformations of GPCR- $\beta$-arrestin complexes mediate desensitization, signaling, and endocytosis," Proceedings of the
National Academy of Sciences, vol. 114, no. 10, pp. 25622567, 2017.

[21] S. L. Ritter and R. A. Hall, "Fine-tuning of GPCR activity by receptor-interacting proteins," Nature Reviews Molecular Cell Biology, vol. 10, no. 12, pp. 819-830, 2009.

[22] D. Lodge, P. Tidball, M. S. Mercier et al., "Antagonists reversibly reverse chemical LTD induced by group I, group II and group III metabotropic glutamate receptors," Neuropharmacology, vol. 74, pp. 135-146, 2013.

[23] N. C. Tronson, Y. F. Guzman, A. L. Guedea et al., "Metabotropic glutamate receptor $5 /$ Homer interactions underlie stress effects on fear," Biological Psychiatry, vol. 68, no. 11, pp. 1007-1015, 2010.

[24] K. Talavera, B. Nilius, and T. Voets, "Neuronal TRP channels: thermometers, pathfinders and life-savers," Trends in Neurosciences, vol. 31, no. 6, pp. 287-295, 2008.

[25] H. Wang, B. Wang, K. P. Normoyle et al., "Brain temperature and its fundamental properties: a review for clinical neuroscientists," Frontiers in Neuroscience, vol. 8, p. 307, 2014.

[26] M. G. Frank, "Circadian regulation of synaptic plasticity," Biology, vol. 5, no. 3, 2016.

[27] J. A. Ronesi, K. A. Collins, S. A. Hays et al., "Disrupted Homer scaffolds mediate abnormal mGluR5 function in a mouse model of fragile X syndrome," Nature Neuroscience, vol. 15, no. 3, pp. 431-440, 2012.

[28] M. Yanagawa, T. Yamashita, and Y. Shichida, "Activation switch in the transmembrane domain of metabotropic glutamate receptor," Molecular Pharmacology, vol. 76, no. 1, pp. 201-207, 2009.

[29] P. Malherbe, N. Kratochwil, F. Knoflach et al., "Mutational analysis and molecular modeling of the allosteric binding site of a novel, selective, noncompetitive antagonist of the metabotropic glutamate 1 receptor," The Journal of Biological Chemistry, vol. 278, no. 10, pp. 8340-8347, 2003.

[30] B. Xiao, J. C. Tu, and P. F. Worley, "Homer: a link between neural activity and glutamate receptor function," Current Opinion in Neurobiology, vol. 10, no. 3, pp. 370-374, 2000.

[31] B. Xiao, J. C. Tu, R. S. Petralia et al., "Homer regulates the association of group 1 metabotropic glutamate receptors with multivalent complexes of Homer-related, synaptic proteins," Neuron, vol. 21, no. 4, pp. 707-716, 1998.

[32] Y. Shiraishi-Yamaguchi and T. Furuichi, "The Homer family proteins," Genome Biology, vol. 8, no. 2, p. 206, 2007.

[33] P. R. Brakeman, A. A. Lanahan, R. O'Brien et al., "Homer: a protein that selectively binds metabotropic glutamate receptors," Nature, vol. 386, no. 6622, pp. 284-288, 1997.

[34] Y. Wang, W. Rao, C. Zhang et al., "Scaffolding protein Homerla protects against NMDA-induced neuronal injury," Cell Death and Disease, vol. 6, no. 8, p. e1843, 2015.

[35] K. Yamamoto, Y. Sakagami, S. Sugiura, K. Inokuchi, S. Shimohama, and N. Kato, "Homer 1a enhances spikeinduced calcium influx via L-type calcium channels in neocortex pyramidal cells," European Journal of Neuroscience, vol. 22, no. 6, pp. 1338-1348, 2005.

[36] Y. Sakagami, K. Yamamoto, S. Sugiura, K. Inokuchi, T. Hayashi, and N. Kato, "Essential roles of Homer-1a in homeostatic regulation of pyramidal cell excitability: a possible link to clinical benefits of electroconvulsive shock," European Journal of Neuroscience, vol. 21, no. 12, pp. 3229-3239, 2005.

[37] L. Yang, L. Mao, Q. Tang, S. Samdani, Z. Liu, and J. Q. Wang, "A novel $\mathrm{Ca}^{2+}$-independent signaling pathway to extracellular 
signal-regulated protein kinase by coactivation of NMDA receptors and metabotropic glutamate receptor 5 in neurons," Journal of Neuroscience, vol. 24, no. 48, pp. 10846-10857, 2004.

[38] L. Mao, L. Yang, Q. Tang, S. Samdani, G. Zhang, and J. Q. Wang, "The scaffold protein Homerlb/c links metabotropic glutamate receptor 5 to extracellular signal-regulated protein kinase cascades in neurons," Journal of Neuroscience, vol. 25, no. 10, pp. 2741-2752, 2005.

[39] P. F. Worley, W. Zeng, G. Huang et al., "Homer proteins in $\mathrm{Ca}^{2+}$ signaling by excitable and non-excitable cells," Cell Calcium, vol. 42, no. 4-5, pp. 363-371, 2007.

[40] A. Tappe, M. Klugmann, C. Luo et al., "Synaptic scaffolding protein Homerla protects against chronic inflammatory pain," Nature Medicine, vol. 12, no. 6, pp. 677-681, 2006.

[41] I. Minami, M. Kengaku, P. S. Smitt, R. Shigemoto, and T. Hirano, "Long-term potentiation of mGluR1 activity by depolarization-induced Homerla in mouse cerebellar Purkinje neurons," The European Journal of Neuroscience, vol. 17, no. 5, pp. 1023-1032, 2003.

[42] J. C. Tu, B. Xiao, J. P. Yuan et al., "Homer binds a novel proline-rich motif and links group 1 metabotropic glutamate receptors with IP3 receptors," Neuron, vol. 21, no. 4, pp. 717-726, 1998.

[43] H. Abe, T. Misaka, M. Tateyama, and Y. Kubo, "Effects of coexpression with Homer isoforms on the function of metabotropic glutamate receptor $1 \alpha$," Molecular and Cellular Neurosciences, vol. 23, no. 2, pp. 157-168, 2003.

[44] J. H. Hu, L. Yang, P. J. Kammermeier et al., "Presol dynamically regulates group I metabotropic glutamate receptors," Nature Neuroscience, vol. 15, no. 6, pp. 836-844, 2012.

[45] P. Crépieux, A. Poupon, N. Langonné-Gallay et al., "A comprehensive view of the $\beta$-arrestinome," Frontiers in Endocrinology, vol. 8, p. 32, 2017.

[46] Y. K. Peterson and L. M. Luttrell, "The diverse roles of arrestin scaffolds in G protein-coupled receptor signaling," Pharmacological Reviews, vol. 69, no. 3, pp. 256-297, 2017.

[47] A. C. Magalhaes, H. Dunn, and S. S. G. S. Ferguson, "Regulation of GPCR activity, trafficking and localization by GPCR-interacting proteins," British Journal of Pharmacology, vol. 165, no. 6, pp. 1717-1736, 2012.

[48] A. Eng, T. Hedrick, and G. Swanson, "mGluR1- $\beta$-arrestin 2 signaling mediates induction of excitatory synaptic plasticity," The FASEB Journal, vol. 29, Supplement 1, pp. 934-935, 2015.

[49] P. Benquet, C. E. Gee, and U. Gerber, "Two distinct signaling pathways upregulate NMDA receptor responses via two distinct metabotropic glutamate receptor subtypes," The Journal of Neuroscience, vol. 22, no. 22, pp. 9679-9686, 2002.

[50] U. Gerber, C. E. Gee, and P. Benquet, "Metabotropic glutamate receptors: intracellular signaling pathways," Current Opinion in Pharmacology, vol. 7, no. 1, pp. 56-61, 2007.

[51] R. H. Oakley, S. A. Laporte, J. A. Holt, M. G. Caron, and L. S. Barak, "Differential affinities of visual arrestin, $\beta$ arrestin1, and $\beta$ arrestin2 for $G$ protein-coupled receptors delineate two major classes of receptors," Journal of Biological Chemistry, vol. 275, no. 22, pp. 17201-17210, 2000.

[52] G. W. Hubert, M. Paquet, and Y. Smith, "Differential subcellular localization of mGluR1a and mGluR5 in the rat and monkey substantia nigra," The Journal of Neuroscience, vol. 21, no. 6 , pp. $1838-1847,2001$.
[53] K. Vincent, V. M. Cornea, Y.-J. I. Jong et al., "Intracellular mGluR5 plays a critical role in neuropathic pain," Nature Communications, vol. 7, article 10604, 2016.

[54] C. a Purgert, Y. Izumi, Y.-J. I. Jong, V. Kumar, C. F. Zorumski, and K. L. O'Malley, "Intracellular mGluR5 can mediate synaptic plasticity in the hippocampus," The Journal of Neuroscience, vol. 34, no. 13, pp. 4589-4598, 2014.

[55] Y.-J. I. Jong, V. Kumar, and K. L. O'Malley, "Intracellular metabotropic glutamate receptor 5 (mGluR5) activates signaling cascades distinct from cell surface counterparts," The Journal of Biological Chemistry, vol. 284, no. 51, pp. 35827-35838, 2009.

[56] V. Kumar, P. G. Fahey, Y.-J. I. Jong, N. Ramanan, and K. L. O'Malley, "Activation of intracellular metabotropic glutamate receptor 5 in striatal neurons leads to up-regulation of genes associated with sustained synaptic transmission including arc/Arg3.1 protein," Journal of Biological Chemistry, vol. 287, no. 8, pp. 5412-5425, 2012.

[57] H. Eishingdrelo and S. Kongsamut, "Minireview: targeting GPCR activated ERK pathways for drug discovery," Current Chemical Genomics and Translational Medicine, vol. 7, pp. 9-15, 2013.

[58] B. Zimmerman, M. Simaan, M.-Y. Akoume et al., "Role of ßarrestins in bradykinin B2 receptor-mediated signalling," Cellular Signalling., vol. 23, no. 4, pp. 648-659, 2011.

[59] E. Cassier, N. Gallay, T. Bourquard et al., "Phosphorylation of $\beta$-arrestin 2 at $\mathrm{Thr}^{383}$ by MEK underlies $\beta$-arrestin-dependent activation of Erk1/2 by GPCRs," eLife, vol. 6, 2017.

[60] E. Khoury, L. Nikolajev, M. Simaan, Y. Namkung, and S. A. Laporte, "Differential regulation of endosomal GPCR/ $\beta$ arrestin complexes and trafficking by MAPK," The Journal of Biological Chemistry, vol. 289, no. 34, pp. 23302-23317, 2014.

[61] A. Beautrait, J. S. Paradis, B. Zimmerman et al., "A new inhibitor of the $\beta$-arrestin/AP2 endocytic complex reveals interplay between GPCR internalization and signalling," Nature Communications, vol. 8, article 15054, 2017.

[62] F. T. Lin, W. E. Miller, L. M. Luttrell, and R. J. Lefkowitz, "Feedback regulation of $\beta$-arrestin1 function by extracellular signal-regulated kinases," The Journal of Biological Chemistry, vol. 274 , no. 23 , pp. 15971-15974, 1999.

[63] J. S. Paradis, S. Ly, É. Blondel-Tepaz et al., "Receptor sequestration in response to $\beta$-arrestin-2 phosphorylation by ERK1/2 governs steady-state levels of GPCR cell-surface expression," Proceedings of the National Academy of Sciences of the United States of America, vol. 112, no. 37, pp. E5160-E5168, 2015.

[64] S. M. Gallagher, C. A. Daly, M. F. Bear, and K. M. Huber, "Extracellular signal-regulated protein kinase activation is required for metabotropic glutamate receptor-dependent long-term depression in hippocampal area CA1," The Journal of Neuroscience, vol. 24, no. 20, pp. 4859-4864, 2004.

[65] J. D. Sweatt, "Mitogen-activated protein kinases in synaptic plasticity and memory," Current Opinion in Neurobiology, vol. 14, no. 3, pp. 311-317, 2004.

[66] R. J. Kelleher, A. Govindarajan, H.-Y. Jung, H. Kang, and S. Tonegawa, "Translational control by MAPK signaling in long-term synaptic plasticity and memory," Cell, vol. 116, no. 3, pp. 467-479, 2004.

[67] S. Coffa, M. Breitman, S. M. Hanson et al., "The effect of arrestin conformation on the recruitment of c-Raf1, MEK1, and ERK1/2 activation," PLoS One, vol. 6, no. 12, article e28723, 2011. 
[68] L. M. Luttrell, F. L. Roudabush, E. W. Choy et al., "Activation and targeting of extracellular signal-regulated kinases by $\beta$-arrestin scaffolds," Proceedings of the National Academy of Sciences of the United States of America, vol. 98, no. 5, pp. 2449-2454, 2001.

[69] L.-M. Mao and J. Q. Wang, "Regulation of group I metabotropic glutamate receptors by MAPK/ERK in neurons," Journal of Nature and Science, vol. 2, no. 12, 2016.

[70] L. R. Orlando, R. Ayala, L. R. Kett et al., "Phosphorylation of the homer-binding domain of group I metabotropic glutamate receptors by cyclin-dependent kinase 5," Journal of Neurochemistry, vol. 110, no. 2, pp. 557-569, 2009.

[71] K. Rosenblum, M. Futter, K. Voss et al., "The role of extracellular regulated kinases I/II in late-phase long-term potentiation," The Journal of Neuroscience, vol. 22, no. 13, pp. 5432-5441, 2002.

[72] S.-R. Jung, C. Kushmerick, J. B. Seo, D.-S. Koh, and B. Hille, "Muscarinic receptor regulates extracellular signal regulated kinase by two modes of arrestin binding," Proceedings of the National Academy of Sciences, vol. 114, no. 28, pp. E5579E5588, 2017.

[73] E. K. Osterweil, D. D. Krueger, K. Reinhold, and M. F. Bear, "Hypersensitivity to mGluR5 and ERK1/2 leads to excessive protein synthesis in the hippocampus of a mouse model of fragile X syndrome," The Journal of Neuroscience, vol. 30, no. 46, pp. 15616-15627, 2010.

[74] H.-H. Ryu and Y.-S. Lee, "Cell type-specific roles of RASMAPK signaling in learning and memory: implications in neurodevelopmental disorders," Neurobiology of Learning and Memory, vol. 135, pp. 13-21, 2016.

[75] J. Min, "Molecular mechanism of beta-arrestin-dependent ERK activation downstream of protease-activated receptor2," 2011, http://www.escholarship.org/uc/item/95084710.

[76] J. A. Ronesi and K. M. Huber, "Homer interactions are necessary for metabotropic glutamate receptor-induced long-term depression and translational activation," Journal of Neuroscience, vol. 28, no. 2, pp. 543-547, 2008.

[77] A. C. Emery, S. Pshenichkin, G. R. Takoudjou, E. Grajkowska, B. B. Wolfe, and J. T. Wroblewski, "The protective signaling of metabotropic glutamate receptor 1 is mediated by sustained, $\beta$-arrestin-1-dependent ERK phosphorylation," Journal of Biological Chemistry, vol. 285, no. 34, pp. 26041-26048, 2010.

[78] R. Rong, J.-Y. Ahn, H. Huang et al., "PI3 kinase enhancerHomer complex couples mGluRI to PI3 kinase, preventing neuronal apoptosis," Nature Neuroscience, vol. 6, no. 11, pp. 1153-1161, 2003.

[79] A. Tappe-Theodor, Y. Fu, R. Kuner, and V. Neugebauer, "Homerla signaling in the amygdala counteracts pain-related synaptic plasticity, mGluR1 function and pain behaviors," Molecular Pain, vol. 7, p. 38, 2011.

[80] I. Obara, S. P. Goulding, J.-H. H. Hu, M. Klugmann, P. F. Worley, and K. K. Szumlinski, "Nerve injury-induced changes in Homer/glutamate receptor signaling contribute to the development and maintenance of neuropathic pain," Pain, vol. 154, no. 10, pp. 1932-1945, 2013.
[81] K. K. Szumlinski, M. H. Dehoff, S. H. Kang et al., "Homer proteins regulate sensitivity to cocaine," Neuron, vol. 43, no. 3, pp. 401-413, 2004.

[82] K. K. Szumlinski, K. E. Abernathy, E. B. Oleson et al., "Homer isoforms differentially regulate cocaine-induced neuroplasticity," Neuropsychopharmacology, vol. 31, no. 4, pp. 768-777, 2006. 

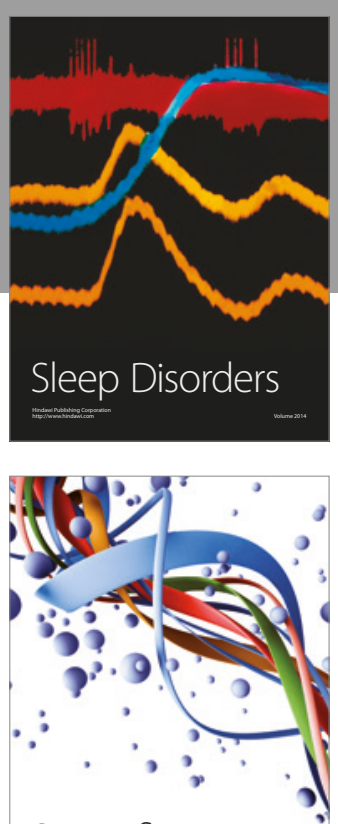

Scientifica
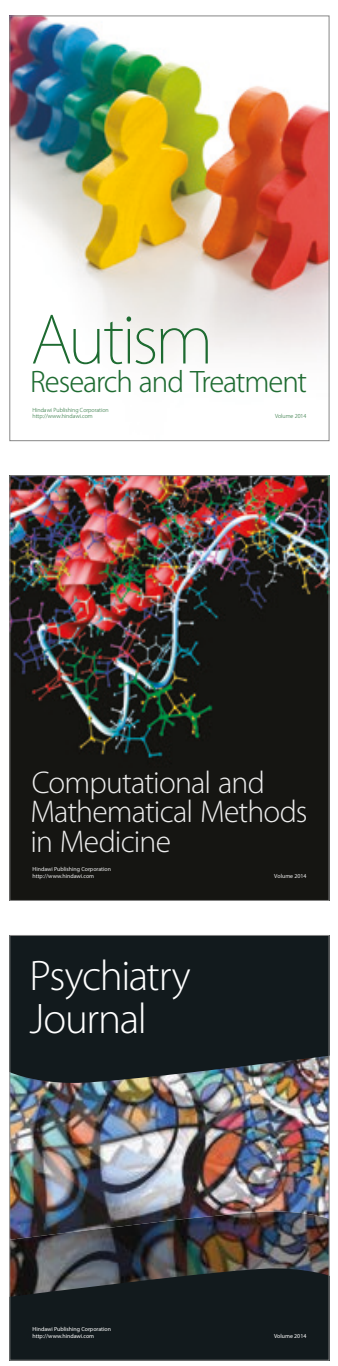
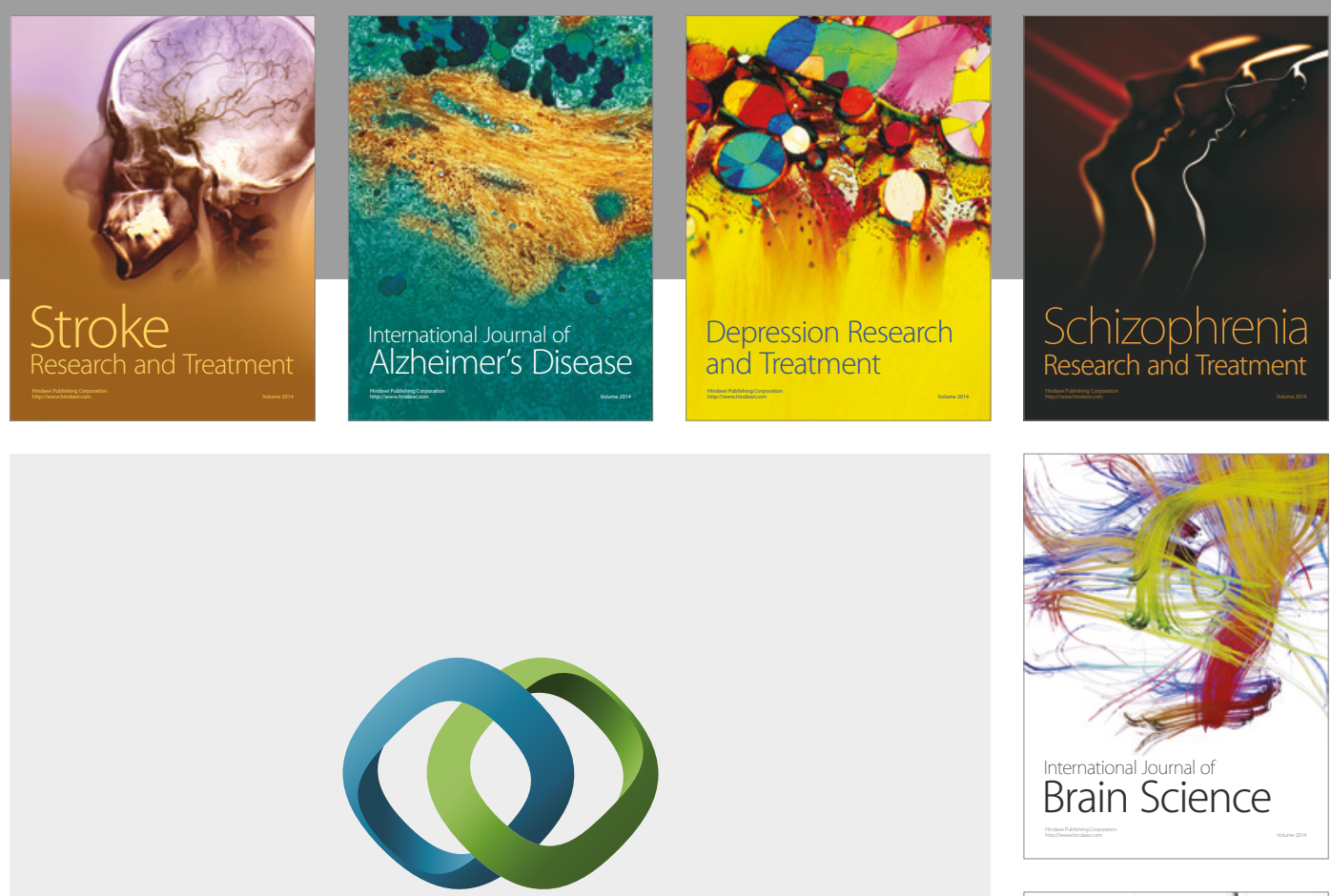

\section{Hindawi}

Submit your manuscripts at

https://www.hindawi.com
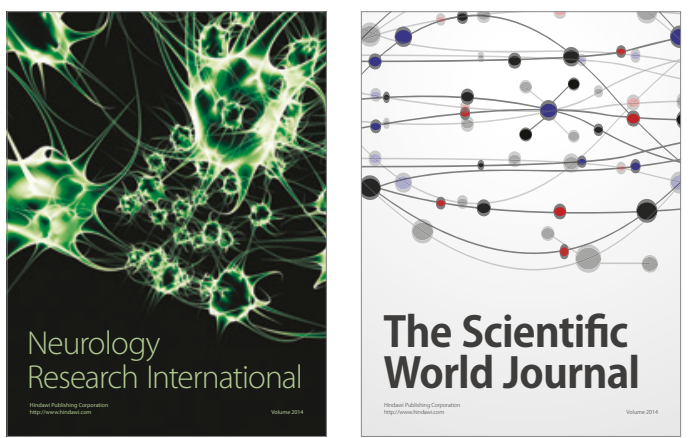

The Scientific World Journal

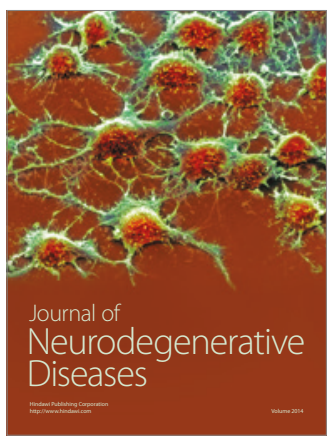

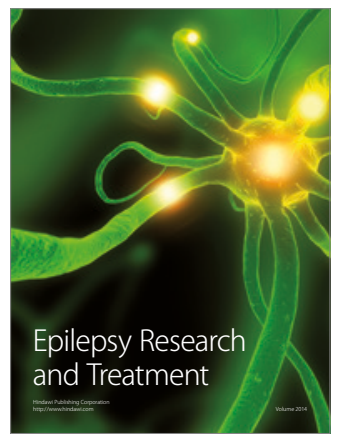

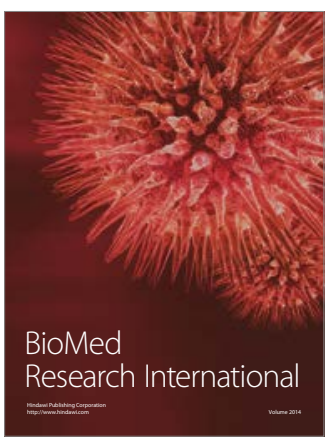

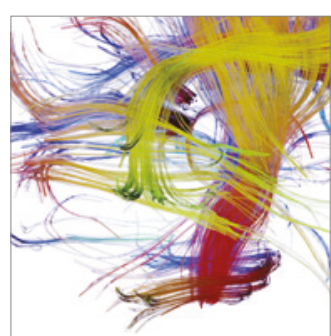

Brain Science

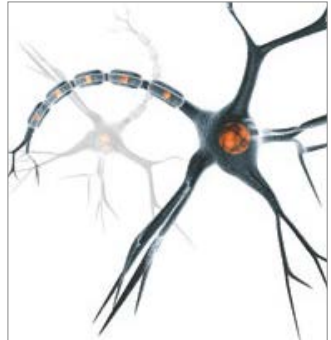

Neural Plasticity
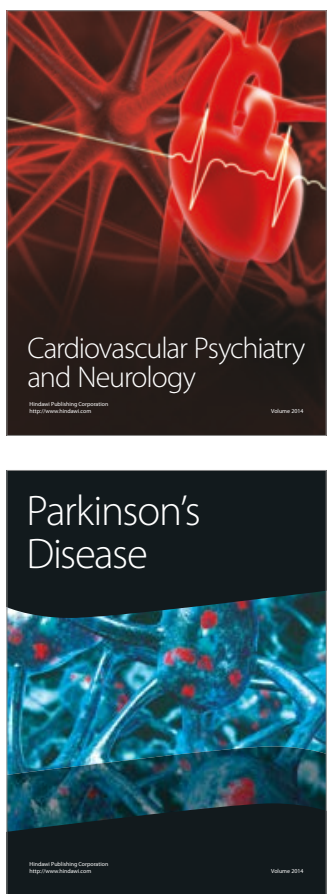